\title{
Analisis Sasaran Keselamatan Pasien Oleh Perawat Di Rumah Sakit
}

\section{Novrial Ahmad Hanif / Ahmadnovrial15@gmail.com}

\author{
Latar belakang
}

\begin{abstract}
Abstrak
Keselamatan (safety) menjadi isu global termasuk di rumah sakit. Rumah sakit wajib mengupayakan pemenuhan sasaran keselamatan pasien yang diatur dalam Peraturan Menteri Kesehatan nomor 11 tahun 2017. Tujuan penelitian ini untuk menganalisis pelaksanaan sasaran keselamatan pasien di rawat inap RSUD Padang Pariaman. Penelitian ini menggunakan metode kualitatif melalui wawancara mendalam, Focus Group Discussion, observasi dan telaah dokumen. Pengumpulan data dilakukan dengan wawancara lima belas orang informan yaitu direktur, kepala bidang pelayanan medik, ketua komite medis, ketua komite keperawatan, kepala instalasi rawat inap, kepala ruangan rawat inap, dokter umum, perawat pelaksana, apoteker, ahli gizi, analis dan radiographer. Komponen yang diteliti mengenai input (kebijakan, pedoman dan Standar Prosedur Operasional (SPO), tenaga, metode, dana, sarana), proses yaitu pelaksanaan sasaran keselamatan pasien, dan output dari capaian penerapan. Hasil penelitian menunjukkan bahwa kebijakan dan SPO sudah lengkap. Tenaga penanggung jawab keselamatan pasien dalam hal ini tim keselamatan pasien belum bekerja optimal. Metode sudah sesuai dengan pedoman yang ada dan dana sudah mencukupi namun pengadaan sarana belum lengkap. Kepatuhan petugas dalam pelaksanaan sasaran keselamatan pasien belum optimal, nilai rata-rata capaian $73,4 \%$ (standar 100\%). Kesimpulannya, pelaksanaan sasaran keselamatan pasien di rawat inap RSUD Padang Pariaman tahun 2018 belum maksimal dan hasil belum mancapai target.
\end{abstract}

Kata Kunci : Sasaran Keselamatan Pasien, Rumah Sakit, Rawat Inap, Kualitatif

\begin{abstract}
Safety has become a global issue as well as in hospitals. The hospital is obliged to effort for the fulfillment of patient safety goals set out in Health Minister Regulation number eleven in 2017. The purpose of this study is to analyze the implementation of patient safety goals in inpatient Padang Pariaman Hospital. This study uses qualitative methods through indepth interviews, Focus Group Discussion, observation and document review. Data collection were conducted by interviewing fifteen informants, namely directors, heads of medical services, heads of medical committees, heads of nursing committees, heads of inpatient installations, heads of inpatient rooms, general practitioners, nursing nurses, pharmacists, nutritionists, analysts and radiographers. Components studied on inputs (policies, guidelines and SPO, personnel, methods, funds, means), the process of implementing the patient's safety objectives, and the outputs of the implementation outcomes. The results showed that the policies and SPO were complete. The personnel responsible for patient safety in this case the patient safety team had not worked optimally. The method was in accordance with the existing guidelines and the funds were sufficient but the procurement of facilities was incomplete. Compliance of officers in the implementation of patient safety goals has not been
\end{abstract}


optimal, the average value of achievement of $73.4 \%$ (standard 100\%). In conclusion, the implementation of the patient's safety objectives at the Padang Pariaman Hospital in 2018 has not been maximized and the results have not reached the target yet.

Keywords : Patient Safety Goals, Hospital, Inpatient, Qualitative

\section{PENDAHULUAN}

- Isu keselamatan pasien melahirkan paradigma baru tentang mutu pelayanan. Mutu pelayanan yang baik saja tidak cukup berarti bagi pasien tanpa memperhatikan bagaimana derajat unsur resiko dan keselamatan yang diterima oleh pasien. Tinggi rendahnya mutu sebanding dengan tingkat ketersediaan fasilitas pelayanan, untuk mencapai keseimbangan terbaik antara risiko dan manfaat keselamatan yang diterima oleh pasien.1 Isu ini praktis mulai dibicarakan kembali pada tahun 2000-an, sejak laporan dari Institute of Medicine (IOM) yang menerbitkan laporan: To Err Is Human, Building A Safer Health System dan memuat data menarik tentang Kejadian Tidak Diharapkan (KTD). Laporan itu mengemukakan penelitian di rumah sakit di Utah dan Colorado serta New York. KTD di Utah dan Colorado ditemukan sebesar 2,9\%, dimana $6,6 \%$ di antaranya meninggal dunia. Sedangkan di New York KTD adalah sebesar $3,7 \%$ dengan angka kematian 13,6\%. Angka kematian akibat KTD pada pasien rawat inap di seluruh Amerika yang berjumlah 33,6 juta per tahun berkisar 44.000-98.000 per tahun. Publikasi WHO pada tahun 2004, mengumpulkan angka-angka penelitian rumah sakit berbagai Negara: Amerika, Inggris, Denmark dan Australia, ditemukan KTD dengan rentang 3,2-16,6\%. Berdasarkan data-data tersebut, berbagai negara segera melakukan penelitian dan mengembangkan sistem keselamatan pasien.2 World Health Organization (WHO) menyatakan keselamatan pasien merupakan masalah kesehatan masyarakat global yang serius. Kesalahan medis dapat disebabkan oleh faktor sistem dan faktor manusia. Insiden keselamatan pasien yang merugikan adalah terkait dengan prosedur bedah (27\%), kesalahan pengobatan (18,3\%) dan kesehatan infeksi terkait perawatan (12,2\%) (WHO, 2017). Sedangkan di Eropa, kejadian pasien dengan risiko infeksi sebanyak $83,5 \%$ dan bukti kesalahan medis menunjukkan 50- 72,3\%.3 National Patient Safety Agency 2017 melaporkan dalam rentang waktu JanuariDesember 2016 angka kejadian keselamatan pasien yang dilaporkan dari Negara Inggris adalah sebanyak 1.879.822 kejadian. Ministry of Health Malaysia melaporkan angka insiden keselamatan pasien dalam rentang waktu JanuariDesember 2013 sebanyak 2.769 kejadian. Dan untuk Negara Indonesia dalam rentang waktu 2006-2011 Komite Keselamatan Pasien Rumah Sakit (KKPRS) melaporkan terdapat 877 KTD.4 Laporan insiden keselamatan pasien di Indonesia berdasarkan propinsi menunjukkan bahwa dari 145 insiden yang dilaporkan terdapat 55 kasus $(37,9 \%)$ terjadi di wilayah DKI Jakarta. Sedangkan berdasarkan jenisnya didapatkan Kejadian Nyaris Cedera (KNC) sebanyak 69 kasus (47,6\%), KTD sebanyak 67 kasus $(46,2 \%)$ dan lainlain sebanyak 9 kasus $(6,2 \%) .5$ Walaupun data ini telah ada secara umum di Indonesia, pelaporan insiden keselamatan pasien di rumah sakit belum dikembangkan secara menyeluruh oleh semua rumah sakit sehingga perhitungan kejadian yang berhubungan dengan keselamatan pasien masih sangat terbatas. Setiap rumah sakit wajib mengupayakan pemenuhan sasaran 
keselamatan pasien. Hal ini telah diatur dalam Peraturan Menteri Kesehatan (Permenkes) nomor 11 tahun 2017. Penyusunan sasaran ini mengacu pada Nine Life-Saving Patient Safety Solutions dari World Health Organization (WHO), yang juga digunakan oleh Komite Keselamatan Pasien Rumah Sakit (KKP-RS) dan Joint Commisions International (JCl). Sasaran keselamatan pasien meliputi tercapainya halhal sebagai berikut: 1) ketepatan identifikasi pasien; 2) peningkatan komunikasi yang efektif; 3) peningkatan keamanan obatobatan yang harus diwaspadai; 4) kepastian lokasi pembedahan yang benar, prosedur yang benar dan pembedahan pada pasien yang benar; 5) pengurangan risiko infeksi terkait pelayanan kesehatan; 6) pengurangan risiko cedera pasien akibat terjatuh. Maksud dari sasaran keselamatan pasien adalah mendorong perbaikan spesifik dalam keselamatan pasien yang menyoroti bidangbidang bermasalah dalam perawatan kesehatan, memberikan bukti dan solusi hasil konsensus yang berdasarkan nasihat para pakar. Rumah Sakit Umum Daerah (RSUD) Padang Pariaman merupakan rumah sakit kelas $\mathrm{C}$ yang beroperasi sejak tahun 2009.7 RSUD Padang Pariaman baru terakreditasi tingkat dasar pada akhir tahun 2017. Upaya-upaya perbaikan telah dilakukan oleh pihak manajemen namun masih diperlukan monitoring dan evaluasi dalam hal keselamatan pasien di RSUD Padang Pariaman. Hasil wawancara peneliti dengan perawat pelaksana di rawat inap RSUD Padang Pariaman pada tanggal 12 Maret 2018, menyatakan bahwa telah terjadi 7 insiden pasien jatuh di rawat inap dalam 2 (dua) tahun terakhir, diantaranya 5 orang pasien jatuh di kamar mandi dan 2 orang pasien jatuh dari tempat tidur. Kondisi ini belum menggambarkan kejadian secara keseluruhan, karena pelaporan insiden di rumah sakit ini belum pernah terlaksana. Selain itu, berdasarkan laporan dan analisa data Healthcare Associated Infections (HAIs) di RSUD Padang Pariaman, angka kejadian infeksi Flebitis pada tahun 2017 masih tinggi yaitu $12,01 \% .8$ Sementara standar pelayanan minimal rumah sakit pada indikator angka kejadian infeksi nosokomial menetapkan standar $\leq 1,5 \%$. 9 Hal ini menunjukkan masih rendahnya penerapan sasaran 5 yaitu pengurangan resiko infeksi terkait pelayanan kesehatan. Berdasarkan pemaparan permasalahan di atas bahwa masih kurangnya pencapaian penerapan enam indikator sasaran keselamatan pasien dan dengan adanya kejadian insiden pasien jatuh serta masih tingginya angka infeksi terkait perawatan kesehatan di rawat inap, maka penulis tertarik untuk meneliti pelaksanaan sasaran keselamatan pasien di rawat inap RSUD Padang Pariaman tahun 2018. Penelitian ini berdasarkan kepada pendekatan sistem yang meliputi aspek masukan (input), proses dan keluaran (output).10

\section{METODE PENELITIAN}

Dilakukan Observasi Berdasarkan Jurnal ANALISIS PELAKSANAAN SASARAN KESELAMATAN PASIEN DI RAWAT INAP RUMAH SAKIT UMUM DAERAH PADANG PARIAMAN Bentuk Penelitiannya adalah Kualitatif. Dan dijelaskan kembali secara deskriptif Dari observasi kemudian akan disesuaikan dengan penggunaan sasaran keselamatan pasien apakah sudah diterapkan dalam kegiatan di rumah sakit atau tidak. Nanti akan disimpulkan kemudian.

\section{PEMBAHASAN}

Terdapat 3 Komponen sasaran keselamatan pasien yaitu meliputi : 
1. Komponen Input
a. Kebijakan
b. Pedoman/SOP
c. Tenaga
d. Metode
e. Dana
f. Sarana

2. Komponen Proses

3. Komponen Output

Akan kita observasi dari berbagai jurnal.

1. Komponen Input

A. Kebijakan

Dalam jurnal "ANALISIS PELAKSANAAN SASARAN KESELAMATAN PASIEN DI RAWAT INAP RUMAH SAKIT UMUM DAERAH PADANG PARIAMAN" Kebijakan yang sudah tetapkan adalah kebijakan dalam bentuk surat Keputusan Direktur Nomor 445/101/RUSD_PDPRM/XI2016 tentang kebijakan sasaran keselamatan pasien. Kebijakan tersebut telah mengacu pada Pemenkes dan KARS antara lain melakukan indentifikasi pasien dengan benar, melakukan komunikasi yang efektif, Meningkatkan keamanan pengelolaan obat yang perlu diwaspadai, memastikan tepat lokasi, tepat prosedur dan tepat pasien operasi, megurangi resiko infeksi terkait pelayanan kesehatan dan mengurangi resiko pasien cedera karena jatuh.

\section{B.Pedoman/SPO}

Dalam jurnal "ANALISIS

PELAKSANAAN SASARAN

KESELAMATAN PASIEN DI RAWAT INAP RUMAH SAKIT UMUM DAERAH PADANG PARIAMAN" Pedoman dan Standar Prosedur Operasiol (SPO) berguna untuk menghemat usaha manajerial, memudahkan pendelegasian wewenang dan menempatkan tanggung jawab, menimbulkan pengembangan metode-metode operasional yang lebih efisien, memudahkan pengawasan, memungkinkan penghematan personalia dan membantu kegiatan koordinasi.

c. Tenaga Tenaga/Sumber Daya Manusia (SDM)

Dalam jurnal "ANALISIS PELAKSANAAN SASARAN KESELAMATAN PASIEN DI RAWAT INAP RUMAH SAKIT UMUM DAERAH PADANG PARIAMAN" Tenaga dalam penelitian ini adalah petugas atau profesional yang terlibat langsung dalam pelaksanaan sasaran keselamatan pasien di rumah sakit.

\section{d. Metode}

$\begin{array}{ll}\text { Dalam } \quad \text { jurnal } & \text { "ANALISIS } \\ \text { PELAKSANAAN } & \text { SASARAN }\end{array}$

KESELAMATAN PASIEN DI RAWAT INAP RUMAH SAKIT UMUM DAERAH PADANG PARIAMAN" Metodenya dengan pemasangan gelang untuk identifikasi pasien, komunikasi efektif dengan teknik SBAR masih belum optimal. budaya menerapkan sasaran keselamatan pasien masih kurang. Petugas menganggap SPO hanya sebatas dokumen untuk memenuhi syarat akreditasi. Perlu adanya supervisi oleh tim keselamatan pasien dan pihak manajemen rumah sakit untuk membimbing dan memotivasi petugas serta untuk mengatasi masalah yang terjadi di rawat inap. Supervisi yang tidak kuat, pelaksanaan tugas yang tidak sesuai rencana dan kegagalan untuk mengkoreksi masalah yang sudah teridentifikasi merupakan kondisi yang 
memudahkan anggota tim melakukan kesalahan dan pelanggaran.

$$
\text { e. Dana }
$$

Dalam jurnal "ANALISIS

PELAKSANAAN SASARAN

KESELAMATAN PASIEN DI RAWAT INAP RUMAH SAKIT UMUM DAERAH PADANG PARIAMAN" didapatkan data bahwa tidak ada anggaran khusus untuk program keselamatan pasien.

\section{f. Sarana}

$$
\text { Dalam jurnal "ANALISIS }
$$

PELAKSANAAN SASARAN

KESELAMATAN PASIEN DI RAWAT INAP RUMAH SAKIT UMUM DAERAH PADANG PARIAMAN" sebagian sudah dilengkapi, namun ada beberapa sarana yang kosong, belum sesuai dengan standar dan rusak. Meskipun anggaran yang ada sudah mulai mencukupi namun masih sering terjadi kekosongan sarana rutin seperti bahan medis habis pakai dan sarana penunjang lainnya. Hal ini disebabkan karena kendala dalam hal pengadaan barang. Upaya dari manajemen rumah sakit ialah membuat laporan permintaan kebutuhan per tahun dari instalasi terkait kebutuhan alat kesehatan, bahan medis habis pakai dan kebutuhan pelayanan lainnya. Hal ini sejalan dengan penelitian di Rumah Sakit Pupuk Kalimantan Timur yang menyatakan bahwa sarana dan fasilitas masih belum maksimal. Dari hasil observasinya terdapat tempat tidur pasien yang belum aman, brankar yang tidak aman dan gelang penanda risiko masih sering kosong.

\section{Komponen Proses}

a. Identifikasi
Dalam jurnal "ANALISIS

PELAKSANAAN SASARAN

KESELAMATAN PASIEN DI RAWAT INAP RUMAH SAKIT UMUM DAERAH PADANG PARIAMAN" Pasien Ketersediaan gelang identitas pasien di RSUD Padang Pariaman mengalami masalah, dimana stok gelang sejak 3 bulan terakhir ini telah habis. Sehingga mengakibatkan pasien yang di rawat inap tidak memakai gelang identitas. Hal ini sangat berisiko terjadi kesalahan dalam mengidentifikasi pasien pada saat tindakan, prosedur diagnostik, dan terapeutik. Hasil penelitian ini sejalan dengan hasil penelitian di Rumah Sakit Khusus Ibu dan Anak PKU Muhammadiyah Kotagede Yogyakarta, yang menunjukkan implementasi sasaran keselamatan pasien pada identifikasi pasien belum sesuai dengan standar akreditasi. Dijelaskan bahwa RSKIA sudah menggunakan gelang identifikasi dalam pelayanan rawat inap namun belum dilakukan sepenuhnya. Hal ini terjadi karena belum ada kebijakan tentang proses identifikasi.

b. Meningkatkan Komunikasi Efektif Dalam jurnal "ANALISIS PELAKSANAAN SASARAN KESELAMATAN PASIEN DI RAWAT INAP RUMAH SAKIT UMUM DAERAH PADANG PARIAMAN". Komunikasi dapat berbentuk lisan dan tertulis. Komunikasi yang mudah terjadi kesalahan kebanyakan terjadi pada saat perintah diberikan secara lisan atau melalui telepon. Agar informasi yang disampaikan oleh perawat ke dokter dapat akurat dan tepat, dalam rangka pengambilan keputusan terhadap situasi klinis yang dihadapi pasien, dapat menggunakan standarisasi komunikasi 
melalui metode Situation Background Assessment Recommendation (SBAR). Berdasarkan hasil observasi, wawancara mendalam dan FGD dapat disimpulkan bahwa peningkatan komunikasi yang efektif di RSUD Padang Pariaman cukup baik dengan menggunakan metode Situation Background Assessment Recommendation (SBAR). Namun pada telaah dokumen, perintah lisan melalui telepon ditulis oleh penerima pesan belum dikonfirmasi oleh pemberi perintah. Begitu juga penyampaian hasil pemeriksaaan diagnostik secara verbal ditulis lengkap, dibaca ulang, dan tapi belum dikonfirmasi oleh pemberi pesan secara lengkap. Hal ini berbeda dengan hasil penelitian di RSUD Sam Ratulangi Tondano, dimana pelaksanaan komunikasi efektif sudah sesuai dengan standar akreditasi rumah sakit versi 2012

\section{c. Peningkatan Keamanan Obat} yang Perlu Diwaspadai

Dalam jurnal "ANALISIS PELAKSANAAN SASARAN KESELAMATAN PASIEN DI RAWAT INAP RUMAH SAKIT UMUM DAERAH PADANG PARIAMAN" Obatobatan menjadi bagian dari rencana pengobatan pasien, manajemen harus berperan secara kritis untuk memastikan keselamatan pasien. Obat-obatan yang perlu diwaspadai (high alert medications) adalah obat yang sering menyebabkan terjadinya kesalahan serius (sentinel event). Obat yang berisiko tinggi menyebabkan dampak yang tidak diinginkan seperti obat-obatan yang terlihat mirip Nama Obat Rupa Mirip (NORUM) atau Look Alike Sound Alike (LASA).6 Berdasarkan hasil telaah dokumen, RSUD Padang Pariaman telah membuat daftar semua obat yang perlu diwaspadai yang disusun berdasarkan data spesifik sesuai dengan regulasi. Untuk obat-obatan high alert sudah memakai stiker berwarna merah dan LASA memakai stiker berwarna kuning. Dari hasil observasi, masih terdapat elektrolit konsentrat di ruangan rawat inap non bedah. Dimana seharusnya hanya tersedia di unit kerja/instalasi farmasi atau depo farmasi. Tempat penyimpanan obat di rawat inap Bedah dan Non Bedah belum sesuai standar, karena obat disimpan di ruang perawat yang suhunya tidak ideal. Lemari khusus penyimpanan obat tidak menggunakan double kunci sehingga keamanan kurang terjamin.

d. Kepastian Tepat Lokasi, Tepat Prosedur dan Tepat Pasien Operasi

$\begin{array}{lrr}\text { Dalam jurnal } & \text { "ANALISIS } \\ \text { PELAKSANAAN } & \text { SASARAN } \\ \text { KESELAMATAN PASIEN } & \text { DI RAWAT } \\ \text { INAP RUMAH SAKIT } & \text { UMUM } \\ \text { DAERAH PADANG } & \text { PARIAMAN" }\end{array}$

Salah lokasi, salah prosedur dan salah pasien operasi adalah sesuatu yang mengkhawatirkan dan tidak jarang terjadi di rumah sakit. Kesalahan ini merupakan akibat dari komunikasi yang tidak efektif anatara anggota tim bedah, kurang/tidak melibatkan pasien didalam penandaan lokasi (site marking) dan tidak ada prosedur untuk verifikasi lokasi operasi. Berdasarkan hasil wawancara mendalam dan observasi mengenai sasaran keselamatan pasien yang keempat ini, untuk memastikan ketepatan lokasi, prosedur dan pasien operasi, RSUD Padang Pariaman telah memiliki checklist dan melibatkan pasien dalam proses penandaan operasi. Namun proses penandaan tersebut tidak selalu 
dilaksanakan di ruangan rawat inap Bedah. Operator sering melakukan penandaan operasi ketika pasien sudah sampai di kamar operasi. Oleh karena itu kepatuhan petugas perlu ditingkatkan agar pelaksanaan sasaran keselamatan pasien khususnya pasien operasi dapat berjalan optimal. Dari hasil telaah dokumen, RSUD Padang Pariaman menggunakan standar prosedur operasional yang dibuktikan dengan surgical checklist dan data pasien yang sudah dilakukan operasi. Namun pelaksanaannya masih belum optimal, karena ada beberapa pasien yang tidak terisi checklistnya.

$$
\text { e. Pengurangan Risiko Infeksi }
$$

Pelayanan Kesehatan

$\begin{array}{lrr}\text { Dalam jurnal } & \text { "ANALISIS } \\ \text { PELAKSANAAN } & \text { SASARAN } \\ \text { KESELAMATAN PASIEN DI RAWAT } \\ \text { INAP RUMAH SAKIT } & \text { UMUM } \\ \text { DAERAH PADANG PARIAMAN" }\end{array}$

Pokok dari eliminasi infeksi adalah cuci tangan (hand hygiene) yang tepat. Pedoman hand hygiene yang berlaku secara internasional bisa diperoleh dari World Health Organization (WHO), rumah sakit mempunyai proses kolaboratif untuk mengembangkan kebijakan dan/atau prosedur yang menyesuaikan atau mengadopsi pedoman hand hygiene yang diterima secara umum untuk implementasi pedoman itu di rumah sakit.18 Berdasarkan telaah dokumen, RSUD Padang Pariaman telah mempunyai pedoman hand hygiene sesuai dengan standar WHO. Hal ini merupakan upaya untuk menurunkan angka infeksi terkait pelayanan kesehatan. Namun upaya tersebut belum sepenuhnya berjalan optimal. Dari hasil observasi, masih ada petugas baik medis maupun paramedis yang belum melaksanakan cuci tangan sesuai dengan prosedur yang telah ditetapkan (5 momen, 6 langkah), termasuk mengedukasi setiap pasien dan keluarga pasien yang di rawat di ruangan rawat inap bedah dan non bedah. Dalam hal sarana cuci tangan, terdapat kekurangan handrub dan tisu di rawat inap Bedah dan non Bedah. Hasil wawancara mendalam dengan beberapa informan menyampaikan bahwa setelah penilaian akreditasi pada akhir tahun 2017, sering terjadi kekosongan bahan habis pakai seperti handrub dan tisu.

\section{g. Mengurangi Risiko Pasien Cedera Akibat Jatuh}

Dalam jurnal "ANALISIS PELAKSANAAN SASARAN KESELAMATAN PASIEN DI RAWAT INAP RUMAH SAKIT UMUM DAERAH PADANG PARIAMAN" Pasien yang pada asesmen awal dinyatakan berisiko rendah untuk jatuh dapat mendadak berubah menjadi berisiko tinggi. Hal ini disebabkan oleh operasi dan/atau anestesi, perubahan mendadak kondisi pasien, serta penyesuaian pengobatan. Banyak pasien memerlukan asesmen selama dirawat inap di rumah sakit. Rumah sakit harus menetapkan kriteria untuk identifikasi pasien yang dianggap berisiko tinggi jatuh. Lokasi spesifik dapat menyebabkan risiko jatuh bertambah karena layanan yang diberikan. Misalnya, terapi fisik (rawat jalan dan rawat inap) memiliki banyak peralatan spesifik digunakan pasien yang dapat menambah risiko pasien jatuh seperti parallel bars, freestanding staircases, dan peralatan lain untuk latihan.18 Berdasarkan hasil FGD dengan perawat pelaksana di rawat inap Bedah dan non 
Bedah, setelah penilaian akreditasi di akhir tahun 2017, perawat tidak melaksanakan asesmen awal, asesmen lanjutan maupun asesmen ulang pada pasien rawat inap yang berisiko jatuh. Hal ini terbukti dalam berkas rekam medis dimana form asesmen risiko jatuh tidak pernah diisi oleh perawat di rawat inap Bedah dan non Bedah. Pengisian form untuk pasien dewasa dengan skala morse dan pasien anak-anak dengan skala humpty dumpty. Sarana prasarana untuk mengurangi risiko pasien cedera akibat jatuh di ruang rawat inap Bedah sudah sesuai dengan standar. Di bangsal pasien dan kamar mandi sudah terpasang handrail. Seluruh tempat tidur pasien sudah memiliki besi pengaman dan tersedia segitiga kuning yang digantung di tempat tidur pasien yang berisiko jatuh. Hal yang berbeda dengan ruangan rawat inap non Bedah dimana belum ada satupun terpasang handrail, sehingga kemungkinan kejadian risiko jatuh cukup tinggi. Hasil penelitian ini sesuai dengan penelitian di RSUD Sam Ratulangi Tondano, dimana pelaksanaan pengurangan risiko pasien jatuh belum sesuai dengan standar akreditasi rumah sakit versi 2012. Hal ini disebabkan karena ketersediaan sarana terkait pengurangan risiko cedera masih belum lengkap seperti pegangan besi di toilet dan tidak semua tempat tidurpasien dilengkapi pengaman. 19

\section{Komponen Output}

Dalam jurnal "ANALISIS

PELAKSANAAN SASARAN

KESELAMATAN PASIEN DI RAWAT INAP RUMAH SAKIT UMUM DAERAH PADANG PARIAMAN" Output adalah kumpulan bagian/elemen yang dihasilkan dari berlangsungnya proses dalam sistem. Output yang diharapkan adalah terlaksananya sasaran keselamatan pasien yang mengacu pada Peraturan Menteri Kesehatan no. 11 tahun 2017 dan Standar Nasional Akreditasi Rumah Sakit (SNARS) yang disusun oleh KARS. Hasil penelitian menunjukkan bahwa pelaksanaan program keselamatan pasien di rawat inap RSUD Padang Pariaman belum mencapai target yang diharapkan. Rata-rata capaian sasaran keselamatan pasien yaitu $73,4 \%$ dimana standar KARS $100 \%$. Pelaporan insiden belum pernah dilaksanakan oleh petugas. Hasil penelitian ini senada dengan penelitian di RSUD Lubuk Basung yang menyatakan bahwa program keselamatan pasien belum tertata dengan baik. Hal ini disebabkan karena adanya keterbatasan dalam pelaksanaannya, meskipun sudah ada kebijakan tertulis.19 Perlu dilakukan upaya perbaikan seperti memenuhi sarana dan prasarana terkait sasaran keselamatan pasien, melaksanakan sosialisasi ulang dan pelatihan patient safety serta monitoring evaluasi oleh tim keselamatan pasien yang melibatkan seluruh staf di rumah sakit. SIMPULAN Pelaksanaan sasaran keselamatan pasien di rawat inap RSUD Padang Pariaman dilihat dari pendekatan sistem, pada komponen input kebijakan dan SPO sudah ada, namun tenaga, metode, dana dan sarana masih belum memenuhi syarat. Pada komponen proses, pelaksanaan enam sasaran keselamatan pasien di rawat inap RSUD Padang Pariaman masih belum mencapai standar, karena dalam pelaksanaannya belum menjadi budaya bagi petugas di rawat inap. Dan pada komponen output, pencapaian target kepatuhan petugas dalam pelaksanaan sasaran keselamatan pasien di rawat inap RSUD Padang Pariaman belum menunjukkan hasil yang diharapkan. Jumlah rata-rata capaian 
keenam sasaran keselamatan pasien yaitu $73,4 \%$ (standar KARS 100\%).

\section{HASIL PEMBAHASAN}

Berdasarkan hasil analisis yang telah dijabarkan sebelumnya. Didapatkan bahwa

\section{Komponen Input}

a. Kebijakan

Dalam kebijakan RUSD Padang Pariaman Telah membuat kebijakan dalam bentuk surat keputusan Direktur Nomor 445/101/RUSD_PD-PRM/XI/2016 tentang kebijakan sasaran keselamatan pasien. Terlihat masih lemah terhadap tim Supervisi keselamatan pasien

\section{b. Pedoman/SPO}

RSUD Padang Pariaman telah menyusun buku pedoman keselamatan pasien yang digunakan sebagai panduan dalam menerapkan sasaran keselamatan pasien. Dari hasil penelitian didapatkan bahwa buku pedoman dan SPO pelaksanaan sasaran keselamatan pasien di RSUD Padang Pariaman disusun sesuai dengan Permenkes dan KARS. Seluruh dokumen sudah tercukupi $100 \%$ khususnya di ruang rawat inap (Bedah dan Non Bedah). Tapi pelaksanaannya masih belum optimal, karena belum menjadi budaya bagi petugas pemberi pelayanan di RS.

\section{c. Tenaga}

Tenaga/Sumber Daya Manusia (SDM) di RUSD Padang Pariaman adalah petugas atau Profesional yang terlibat langsung dalam pelaksanaan sasaran keselamatan pasien di rumah sakit

\section{d. Metode}

Metode yang digunakan di RUSD Padang Pariaman adalah metode pemasangan gelang untuk identifikasi pasien.

\section{e. Dana}

Dana di RUSD Padang Pariaman bahwa tidak ada anggaran khusus untuk program keselamatan pasien.

f. Sarana

Saran di RUSD Padang Pariaman untuk keselamatan pasien sebagian besar sudah dilengkapi, namun ada beberapa sarana yang kosong.

2. Komponen Proses
a. Identifikasi Pasien

Ketersedian gelang identifikasi pasien di RUSD Padang Pariaman mengalami masalah dalam 3 bulan terakhir ini telah habis.
b. Meningkatkan Komunikasi Efektif

Berdasarkan hasil observasi, wawancara mendalam dan FGD dapat disimpulkan bahwa peningkatan komunikasi yang efektif di RSUD Padang Pariaman cukup baik dengan menggunakan metode Situation Background Assessment Recommendation (SBAR).

c. Peningkatan Keamanan obat yang perlu diwaspadai

Berdasarkan hasil telaah dokumen, RSUD Padang Pariaman telah membuat daftar semua obat yang perlu diwaspadai yang disusun berdasarkan data spesifik sesuai dengan regulasi. Untuk obat-obatan 
high alert sudah memakai stiker berwarna merah dan LASA memakai stiker berwarna kuning.

d. Kepastian Tepat Lokasi, Tepat Prosuder dan Tepat Pasien Operasi

Dari hasil telaah dokumen, RSUD Padang Pariaman menggunakan standar prosedur operasional yang dibuktikan dengan surgical checklist dan data pasien yang sudah dilakukan operasi. Namun pelaksanaannya masih belum optimal, karena ada beberapa pasien yang tidak terisi checklistnya.

\section{e. Pengurangan Risiko Infeksi Pelayanan Kesehatan}

Dalam hal sarana cuci tangan, terdapat kekurangan handrub dan tisu di rawat inap Bedah dan non Bedah. Hasil wawancara mendalam dengan beberapa informan menyampaikan bahwa setelah penilaian akreditasi pada akhir tahun 2017, sering terjadi kekosongan bahan habis pakai seperti handrub dan tisu.

\section{f. Mengurangi Risiko Pasien Cedera Akibat jatuh}

Hasil penelitian ini sesuai dengan penelitian di RSUD Sam Ratulangi Tondano, dimana pelaksanaan pengurangan risiko pasien jatuh belum sesuai dengan standar akreditasi rumah sakit versi 2012. Hal ini disebabkan karena ketersediaan sarana terkait pengurangan risiko cedera masih belum lengkap seperti pegangan besi di toilet dan tidak semua tempat tidurpasien dilengkapi pengaman.

\section{Komponen Output}

Perlu dilakukan upaya perbaikan seperti memenuhi sarana dan prasarana terkait sasaran keselamatan pasien, melaksanakan sosialisasi ulang dan pelatihan patient safety serta monitoring evaluasi oleh tim keselamatan pasien yang melibatkan seluruh staf di rumah sakit.

\section{SIMPULAN}

Pelaksanaan sasaran keselamatan pasien di rawat inap RSUD Padang Pariaman dilihat dari pendekatan sistem, pada komponen input kebijakan dan SPO sudah ada, namun tenaga, metode, dana dan sarana masih belum memenuhi syarat. Pada komponen proses, pelaksanaan enam sasaran keselamatan pasien di rawat inap RSUD Padang Pariaman masih belum mencapai standar, karena dalam pelaksanaannya belum menjadi budaya bagi petugas di rawat inap. Dan pada komponen output, pencapaian target kepatuhan petugas dalam pelaksanaan sasaran keselamatan pasien di rawat inap RSUD Padang Pariaman belum menunjukkan hasil yang diharapkan. Jumlah rata-rata capaian keenam sasaran keselamatan pasien yaitu $73,4 \%$ (standar KARS 100\%).

\section{SARAN}

Diharapkan kepada direktur RSUD Padang Pariaman dan jajarannya agar melakukan pembinaan dan pengawasan kegiatan program keselamatan pasien yang dilaksanakan oleh Tim Keselamatan Pasien Rumah Sakit (TKPRS) secara berkala. Menyiapkan sarana dan prasarana untuk kebutuhan program keselamatan pasien sesuai dengan standar akreditasi. Bagi tim keselamatan pasien agar dapat menyusun program kerja tahunan yaitu melaksanakan motivasi, edukasi, konsultasi, pemantauan dan penilaian tentang penerapan program keselamatan 
pasien, melaksanakan pelatihan, melakukan pencatatan, pelaporan insiden, analisis insiden temasuk melakukan RCA (Root Cause Analysis) dan mengembangkan solusi untuk meningkatkan keselamatan pasien.

\section{DAFTAR PUSTAKA}

1. Cahyono, Agung. (2015). Hubungan Karakteristik dan Tingkat Pengetahuan Perawat Terhadap Pengelolaan Keselamatan Pasien Di Rumah Sakit. Jurnal Ilmiah Widya : Vol. 3 Nomor 2.

2. Diah, dkk. (2015). Pengetahuan Tenaga Kesehatan Dalam Sasaran Keselamatan Pasien di Rumah Sakit Sumatera Utara. Idea Nursing Journal Vol VI No. 2

3. Fatimah, I. (2012).Hubungan Pengetahuan, Motivasi dan Supervisi Dengan Kinerja Perawat Dalam Melaksanakan Patient Safety di RSUD Lambuang Baji. Makassar: Universitas Hasanudin

4. Iswati. (2013). Penerapan Sasaran Keselamatan Pasien di Rumah Sakit. Jurnal Akademi Keperawatan Adi Husada

5. Lombogia A, Julia R, Michael K. Hubungan Perilaku dengan Kemampuan Perawat dalam Melaksanakan Keselamatan Pasien (Patient safety) di Ruang Akut Instalasi Gawat Darurat RSUP Prof. Dr. R. D. Kandou Manado. Ejournal Keperawatan (e-Kp). 2016; 4(2):1-8. [diakses 12 Januari 2018] available at: https://ejournal.unsrat.ac.id.

6. Potter, P.A., \& Perry.A.G. (2009). Keperawatan Dasar. Ed. 4. Alih bahasa : Renata dkk. Jakarta : EGC.7

7. Reno Afriza Neri, Yuniar Lestari, dan Husna Yetti. (2018). ANALISIS

PELAKSANAAN SASARAN KESELAMATAN PASIEN DI RAWAT INAP RUMAH SAKIT UMUM DAERAH PADANG PARIAMAN. Jurnal Kesehatan Andalas. 2018; 7(Supplement 4)

8. Simamora, R. H. (2018). Buku ajar keselamatan pasien melalui timbang terima pasien berbasis komunikasi efektif SBAR. Medan: USUpress.

9. Simamora, R. H. (2020). Learning of Patient Identification in Patient Safety Programs Through Clinical Preceptor Models. Medico Legal Update, 20(3), 553-556.

10. Sumangkut N S I, E Kristanto, J Pongoh. 2017. Evaluasi Penatalaksanaan Sasaran Keselamatan Pasien Di Rumah Sakit Umum GMIM Kalooran Amurang. Manado. Universitas Sam Ratulangi. Community Health 11. Tutiany, Lindawati \& Paula. (2017). Bahan Ajaran Keperawatan : Manajemen Keselamatan Pasien. Kementerian Kesehatan RI.

12. Widiasari, dkk. (2019). Kepuasan Pasien Terhadap Penerapan Keselamatan Pasien Di Rumah Sakit. Jurnal Keperawatan Indonesia, 2019,22 (1), 43 - 52. 
